THE JOURNAL OF TEACHING ENGLISH FOR SPECIFIC AND ACADEMIC PURPOSES Vol. 6, $\mathrm{N}^{\mathrm{o}} 3$, 2018, pp. 353-364

UDC: $811.111^{\prime 2} 255.4: 371.4$

https://doi.org/10.22190/JTESAP1803353B

\title{
EXAMINING PEDAGOGICAL CONTENT KNOWLEDGE OF ESP TEACHERS
}

\author{
Dragana Božić Lenard ${ }^{1}$, Ivan Lenard ${ }^{2}$ \\ ${ }^{1}$ Faculty of Electrical Engineering, Computer Science and Information Technology Osijek, Croatia \\ ${ }^{2}$ Primary School Ladimirevci, Croatia \\ E-Mail: dragana.bozic@ferit.hr
}

\begin{abstract}
A prerequisite for successful knowledge transfer is for a teacher to have sound pedagogical content knowledge, i.e. to have understanding of students' learning abilities, educational context, content and to employ appropriate instructional techniques. The aim of this paper was to study English for Specific Purposes (ESP) teachers' teaching experience. For that purpose, 47 ESP teachers working at 7 Croatian universities voluntarily participated in an anonymous survey whose results were processed in SPSS. The results indicated that the teachers compile their teaching materials consulting various available resources, but rarely cooperate with their specialized course colleagues despite recognizing the importance and fruitfulness of such cooperation. In spite of feeling less confident about content knowledge, the teachers prepare thoroughly and present content in an appealing and interesting way. Finally, the teachers carry out course evaluations implementing students' suggestions into their courses, all of which point to the teachers' carefully considering all elements of the teaching process constantly aiming to improve both their own and students' performance.
\end{abstract}

Key words: pedagogical content knowledge, ESP teachers, survey

\section{INTRODUCTION}

Teaching is a very complex process, which includes several stages and a number of skills one needs to acquire in order to perform the job efficiently and effectively. Contrary to a common non-professional belief, teaching is more than just transferring knowledge to students. This is especially evident when teaching English for Specific Purposes (ESP) courses, which are learner-centered specific purpose types of language instruction. ESP courses need to be focused on students' occupational learning purposes, include contents appropriate for students' communication needs and be oriented towards learning outcomes of educating students to be communicatively proficient in their respective fields. However, in spite of being needs-oriented and learner-centered, they are also teacher-dependent because ESP teachers play the pivotal roles of course designers, material developers, researchers and evaluators, consequently having major autonomy in the teaching process. To paraphrase, in order to teach ESP classes, teachers need to develop a special approach of teaching English through specialized contents thus mastering both content and pedagogy.

Submitted August $23^{\text {rd }}, 2018$, accepted for publication October $17^{\text {th }}, 2018$ 


\section{THEORETICAL OVERVIEW}

Up to 1986 , it was a common belief that a requirement a teacher needs to meet is content knowledge. In a revised approach proposed by Ball, Thames and Phelps (2008), there are three categories of content knowledge, namely common content knowledge, horizon content knowledge and specialized content knowledge. Common content knowledge is subject-specific but not teaching-specific knowledge. For example, native and foreign language teachers use language rules and principles to explain basic tenses, but anyone with high school working knowledge of languages would be able to explain it, so this knowledge is not unique to language teachers. Horizon content knowledge is knowledge of connecting ideas across the content domain. For example, one would not expect for primary school English classes to include the topic of articles, but it would be helpful if a teacher explaining (non)countable nouns connect it to the article usage. Specialized content knowledge is only used by teachers and solely for teaching purposes. For example, an English for Academic Purposes (EAP) teacher needs to have a specialized understanding of students composing sentences in either active or passive voice in order to better understand student strategies and sources of errors.

Built on the premise that content knowledge does not imply successful knowledge transfer, Shulman (1986) coined the amalgam pedagogical content knowledge (PCK) which comprises content and pedagogical knowledge. Shulman's concept is based on two crucial teaching concepts - understanding and presenting. A teacher needs to have content knowledge and take into consideration the teaching context, namely cognitive and sociocultural aspects of his/her students, in order to present content knowledge in the most efficient and appealing way, i.e. PCK combines content and pedagogy - teacher's understanding of a topic with appropriate instructional strategies. As Shulman (1987: 15) argued "PCK is the capacity of a teacher to transform the content knowledge he or she possesses into forms that are pedagogically powerful and yet adaptive to the variations in ability and background presented by the students." Starting from the premise that content knowledge is a prerequisite for one to teach, Shulman (1987: 8) listed seven categories each teacher needs to bear in mind:

1. General pedagogical knowledge of classroom organization and management;

2. Knowledge of students and their characteristics;

3. Knowledge of educational contexts;

4. Knowledge of educational aims, purposes and values;

5. Content knowledge;

6. Curriculum development;

7. Pedagogical content knowledge.

He suggested usage of instructional strategies such as analogies, illustrations and demonstrations, to make contents more comprehensible. On the other hand, Shulman believed that students might gain misconceptions through prior learning experiences or fail to realize how concepts interrelate, so teachers need to recognize such problems and help students solve them. Teachers with sound pedagogical content knowledge understand how students construct knowledge and acquire skills, i.e. pedagogical content knowledge includes the understanding of social, developmental and cognitive learning theories.

A growing body of research (Abell, 2007; Zembylas, 2007; Hill, Ball and Shiling, 2008; Park and Oliver, 2008; Chick, 2009) re-examined Shulman's concept of PCK and 
explored it in different subject areas. The review of PCK has led to establishing three PCK categories, namely knowledge of content and students, knowledge of content and teaching and knowledge of curriculum. Knowledge of content and students refers to teacher's understanding of students' learning (dis)abilities and common mistakes they make. Knowledge of content and teaching includes teacher's understanding of content organization, planning, decision-making and task organization. Knowledge of curriculum refers to teacher's understanding of sequencing, topics and activities organization. Generally, the proposed PCK categories summarize Shulman's seven categories without greater changes of their contents. It is of utmost importance that teachers are aware of PCK and that they carefully take into account all stages of the teaching process because research have pointed to a positive correlation of PCK and students' learning outcomes (Dapaepe, Verschaffel and Kelchtermans, 2013).

\section{MeTHODOLOGY}

The paper aims to examine ESP teachers' experience in the process of teaching. For that purpose, a survey was made in Google docs. It consisted of 45 questions ranging from yes/no and multiple-choice to five-point rating scales and open-ended questions. The survey was divided in three parts - demographics questions, planning and material designing questions and teaching, evaluating and challenges questions. The survey was sent via e-mail to teachers teaching ESP courses at 7 Croatian universities. Participation in the survey was anonymous and voluntary. Given the fact that a list of ESP teachers does not exist and some teachers share the official departmental e-mail the survey was sent to, we can only approximately determine that $50 \%$ of the Croatian ESP teachers (47 responses) participated in the survey, which is the weak point of this research since we cannot make generalizations based on the survey results.

\subsection{Participants}

Total of 47 ESP teachers, 46 female (98\%) and 1 male (2\%), voluntarily participated in the survey, thus representing the population of the ESP teachers working at 7 Croatian universities.

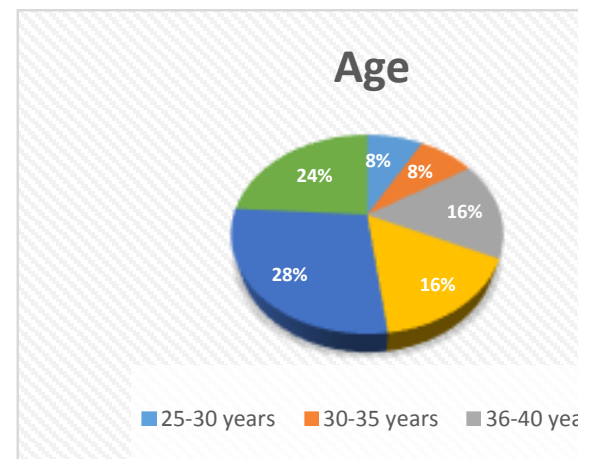

Fig. 1 ESP teachers' age

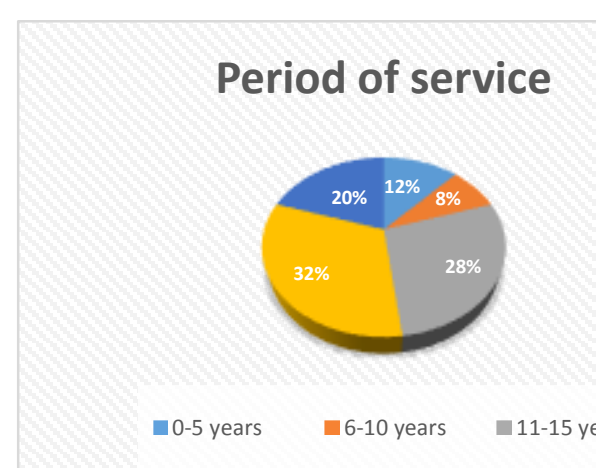

Fig. 2 Period of service in higher education 
As is clear from Fig. 1 and 2, the participants represent all age groups and have been working in higher education for a different number of years, hence the diversity of the participants' age and teaching experience speaks in favor of the sample representation. Sixteen percent of the participants have a Bachelor's degree in the English language and literature, $48 \%$ have a Master's degree in the English language and literature and 36\% have a doctorate degree in Linguistics or other Humanities' subfields. Pursuant to their educational levels, $14 \%$ of the participants work at the position of an assistant, $16 \%$ at the position of an assistant professor and $68 \%$ as senior lecturers. The participants teach different ESP courses ranging from ESP for all branches of engineering and medical sciences to ESP for business and social sciences subfields. The majority of the participants $(64 \%)$ have never had any ESP training and those who have had $(36 \%)$, attended conferences, summer schools and workshops.

\subsection{Instrument}

The survey was created in Google docs due to easier distribution and data processing. The survey results were uploaded in the software for statistical analysis SPSS where we conducted descriptive statistics and one-way analysis of variance (ANOVA) tests to examine if mean differences between different groups of participants are significant on dependent variables.

\section{RESULTS AND DISCUSSION}

Teaching is a very complex and multi-level process, which includes needs assessment, planning, material designing, teaching and evaluating. In the needs-analysis phase, the ESP teacher performs the role of a researcher who studies students' learning and communication needs taking into account cognitive and socio-cultural aspects. In the next phase, the ESP teacher sets course objectives and embarks on materials designing. Then, the teacher instructs and facilitates learning of ESP. In the subsequent phase, the teacher assesses students' knowledge and classroom performance carrying out achievement tests. Finally, the teacher designs and conducts a course evaluation thus studying his/her teaching performance and course aims realization.

\subsection{Planning and material designing}

Sixty eight percent of the teachers do not carry out placement tests and, naturally, they do not adjust their teaching materials according to placement test results. This is probably due to a lack of time for conducting placement tests and consequently adjusting teaching materials to students' needs. Furthermore, if interested, teachers can request students' state graduate exam results from student administration offices and get an approximate overview of students' prior knowledge. Even though only $32 \%$ of the teachers carry out placement tests, $48 \%$ of them carry out a needs analysis and adjust their class materials and contents to needs analysis results, which is crucial for curriculum development according to numerous researchers such as Atefi Boroujeni and Moradian Fard (2013), Hossain (2013), Chin-Ling (2016), Sahli (2016), Alsamadani (2017) to name a few. The percentage of the teachers carrying out needs analysis is not very high possibly due to administration restrictions on changing contents and teaching materials 
without prior authorization of universities. If teachers had more freedom in this respect, they would probably invest more time into adapting their teaching materials and contents pursuant to annual needs analysis results.

Each planning and material designing includes thorough consideration and anticipation of what students will most benefit from in their future job positions so teachers have to frequently decide which skills to teach more. Fig. 3 illustrates the skills to be acquired in the ESP classes of our participants.

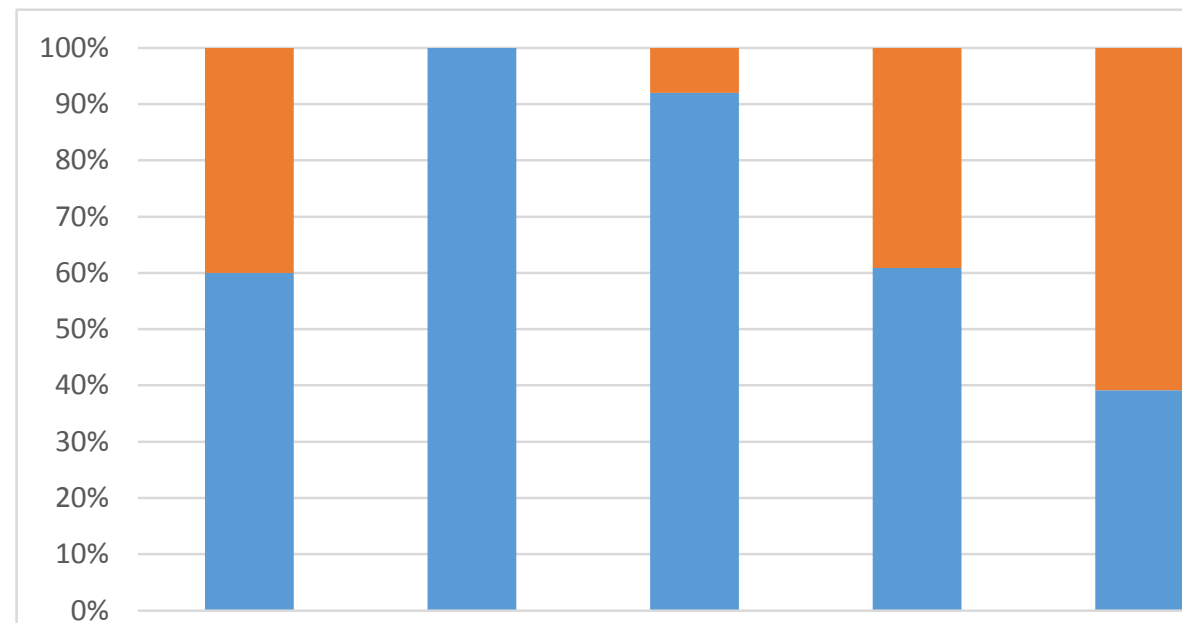

Fig. 3 An overview of the preferred skills taught in ESP classes

It is clear that the teachers put a strong emphasis on teaching vocabulary, speaking and presentation skills, which is rather expected as for the majority of students, ESP classes are the first (and only) opportunity to learn specialized vocabulary. Teaching and learning specialized vocabulary as a perennial aspect of continuous language teaching and learning was also recognized in recent studies by Gifford (2013), Gorska-Porecka (2013) and Božić Lenard et al. (2018). Teaching speaking and presentation skills is of paramount importance because regardless of the field of study, graduates have to present their research/work results and they will probably be required to present their company's work to a wider (international) audience on conferences, round tables, meetings, etc., hence our research results are in accord with the most recent studies on the issue of teaching communication skills by Deveci and Nunn $(2017 ; 2018)$ and Božić Lenard and Pintarić (2018). Although taught, grammar is not as represented probably due to its extensive presence during primary and secondary education. Writing skills, on the other hand, are probably not as represented due to their time-consuming nature. The next several questions on the importance of teaching the aforementioned skills speak in favor of the provided explanations. Seventy two percent of the teachers believe teaching grammar is very or extremely important, $76 \%$ think that about teaching writing skills and $96 \%$ rate vocabulary and speaking and presentation skills with the highest rates. To put it differently, the teachers recognize the importance of teaching (or continuing) all skills but due to a lack of time, they have to prioritize and teach the most important and sought skills. Only $56 \%$ of the teachers believe teaching problem-solving skills are very or 
extremely important, which might be explained with the nature of ESP classes that do not involve specialized problem-solving skills and insufficient technical knowledge ESP teachers have for teaching problem-solving skills.

In order to teach any skill, teachers need to plan and prepare teaching materials, which, when teaching ESP, can be challenging. Teaching materials can range from readymade materials published by well-recognized publishers to teacher-compiled materials. As presented in Fig. 4, the teachers combine a variety of teaching materials in ESP classes.

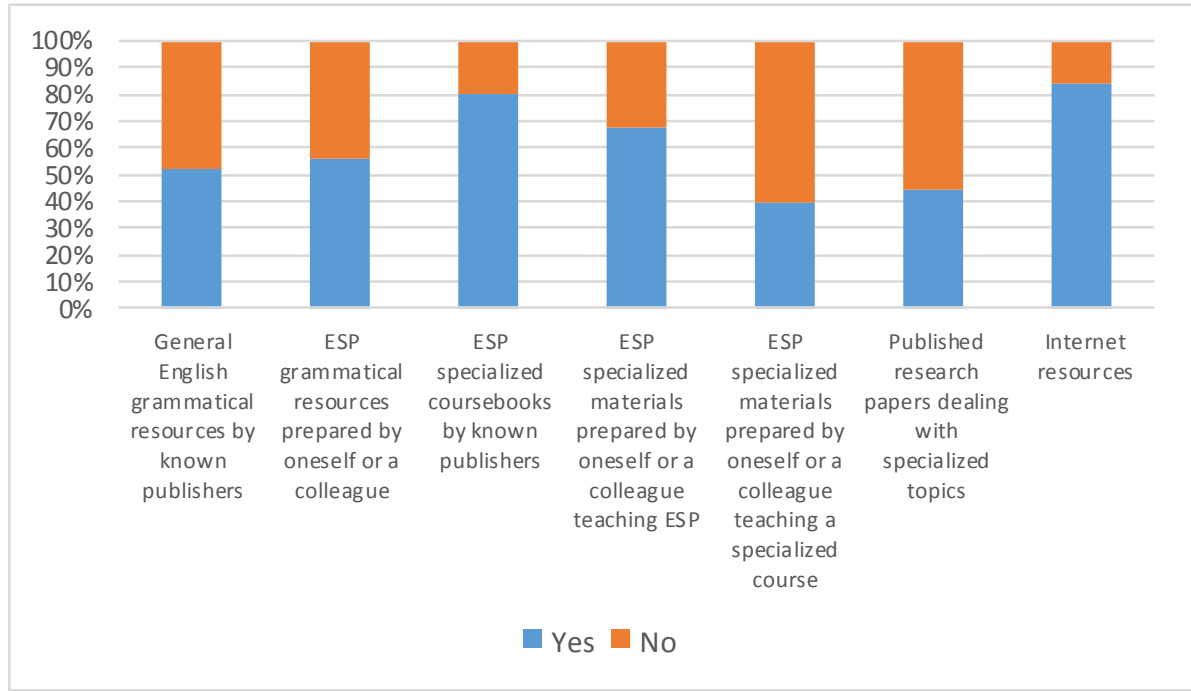

Fig. 4 Types of teaching materials

The results clearly indicate that the ESP teachers go to great lengths to compile their teaching materials using every available source, which is consistent with GorskaPorecka's (2013) results. Sixty eight percent of the teachers adjust their teaching resources every year and $28 \%$ every two years, which is very time-consuming. They frequently indicated the unavailability of ready-made materials and consequently time management in preparing materials as one of the greatest challenges they face which was also recognized by Hutchinson and Waters (2010), Medrea and Rus (2012), Upton (2012), and Lesiak-Bielawska (2015). Only $40 \%$ of the teachers cooperate with subject specialists and jointly compile teaching materials. This is a rather disappointing percentage because the cooperation of an ESP and a subject specialist is the most natural and productive synergy, therefore being something to encourage. However, in spite on not cooperating with content teachers on preparing teaching materials, when preparing for their classes, some ESP teachers do consult their colleagues when in doubt. Yet, the majority of them conduct research, read specialized articles, review available materials, search the Internet and learn while proofreading articles and in that way prepare for their classes. 


\subsection{Pedagogical and content knowledge}

Content knowledge is the knowledge of the subject learnt or taught and it contains concepts related to the teaching topics, concepts, theories, evidence, established practices and problem-solving skills (Shulman, 1986; Mishra and Koehler, 2006), hence, it is a prerequisite for teaching a subject. However, having content knowledge does not imply successful transfer of the knowledge to students. Teachers need to bear a lot of variables in mind for the successful performance of the job, so we decided to examine if they do. Ninety two percent of the teachers believe they have very good or excellent knowledge about the context of their lessons, which is a result of their good preparation. However, $48 \%$ think they have very good and only $20 \%$ excellent knowledge about relations, rules and formulas related to topics they teach. This comes as no surprise because ESP teachers teach concepts related to other (frequently completely unrelated) field of study so they feel reluctant to say they have knowledge of something they did not master. What does come as surprise is that the teachers who teach from 16 to 20 years are the most insecure believing they have only good knowledge about relations, rules and formulas, i.e. they are significantly less confident about their knowledge than the teachers who teach for more than 20 years $(\mathrm{p}=.011)$. As we further ask questions about more detailed specialized knowledge, the level of confidence naturally decreases. Twenty percent of the teachers think they have excellent, $36 \%$ very good, $24 \%$ good, $16 \%$ sufficient and $4 \%$ insufficient knowledge about the theory, axioms, theorems, etc., related to topics they teach. Interestingly, the two least confident groups of teachers are the ones teaching from 11 to 15 and from 16 to 20 years. One would expect for the less experienced teachers to be the most insecure but they either invest more time into preparing for their units, thus proving themselves, or they feel embarrassed to confess their specialized knowledge limitations.

According to Shulman (1986), pedagogical content knowledge surpasses mere subject knowledge and includes representational forms of ideas, illustrations, explanations, analogies, appreciation of the teaching context as well as students' educational background and age, etc. Sixty percent of the teachers believe they can use multi representations such as tables, graphs, diagrams and equations to teach concepts related to their course, while $40 \%$ of the teachers are not very confident in using multi representations. Since such forms are usually used to represent ideas in the fields not related to humanities, reluctance the ESP teachers feel about using them is natural. Furthermore, $88 \%$ of the teachers think they can present ideas systematically (from concrete to abstract) and while doing that, $76 \%$ of the teachers successfully connect old and new specialized topic contents. When teaching, $84 \%$ of the teachers use everyday examples related to specialized topics and $72 \%$ of them are confident to answer students' questions related to specialized topics. Ninety two percent of the teachers believe they use teaching methods, techniques and instruments suitable for specialized topics they teach. Our results on pedagogical content knowledge realization support the previous results on the issue (Akbari and Moradkhani, 2012; Moradkhani et al., 2013). In comparison to the lower percentage related to content knowledge, the high percentage of confidence in using appropriate teaching methods, techniques and instruments, i.e. pedagogical content knowledge, seems reasonable and expected because the teachers were educated to apply appropriate teaching methods in explaining contents to students. It would be interesting to survey students on the comparison of ESP and subject specialists as to which group uses pedagogical content knowledge in a more efficient and 
appealing way. We believe that in spite of having less content knowledge, ESP teachers would be rated as the ones presenting contents more efficiently and interestingly.

Taking the nature of ESP courses in mind, a close cooperation of ESP and content teachers seems like the most natural thing, so we surveyed the participants' experience regarding team teaching. All participants think that the cooperation is very $(20 \%)$ or extremely (80\%) important, which supports Little and Hoel's (2011) and Fenollera et al.'s (2012) ideas. Nevertheless, only $40 \%$ of the participants cooperate with and are assisted by content teachers. The participants did not answer this question as a homogenous group, i.e. the participants who work at the positions of senior lecturers believe that ESP and content teachers should closely cooperate significantly more than their colleagues working as assistant professors $(\mathrm{p}=.047)$. It seems possible that the level of education (doctoral degree) and more demanding requirements assistant professors have to meet for job promotion have resulted in more autonomy, work independence, individualism and self-confidence. Furthermore, only $24 \%$ of the participants learned about learning outcomes from their subject specialist colleagues. Since it was not our research aim, we can only speculate about reasons of the lack of cooperation. In spite of the participants recognizing the need to cooperate, its reciprocal nature points to both parties investing time and putting in an effort to achieve the desired effect. Since ESP teachers, who possess pedagogical knowledge, would gain content knowledge out of this cooperation, i.e. fully benefit from the cooperation, they might want to put in an extra effort to make the cooperation work.

\subsubsection{Evaluation}

Evaluating students' knowledge and their feedback on teachers' methods and techniques is vitally important for an educational process because it gives guidance on both students' and teachers' accomplishments. Ninety six percent of the teachers believe they can effectively employ appropriate techniques to evaluate their students' class performance and $80 \%$ are confident they can adequately use positive and negative reinforcements in order to fulfil their aims. However, students are not the only group to be evaluated, i.e. students get a chance to evaluate their teachers in various respects. Eighty percent of the teachers carry out course evaluations and the elements being evaluated are illustrated in Fig. 5.

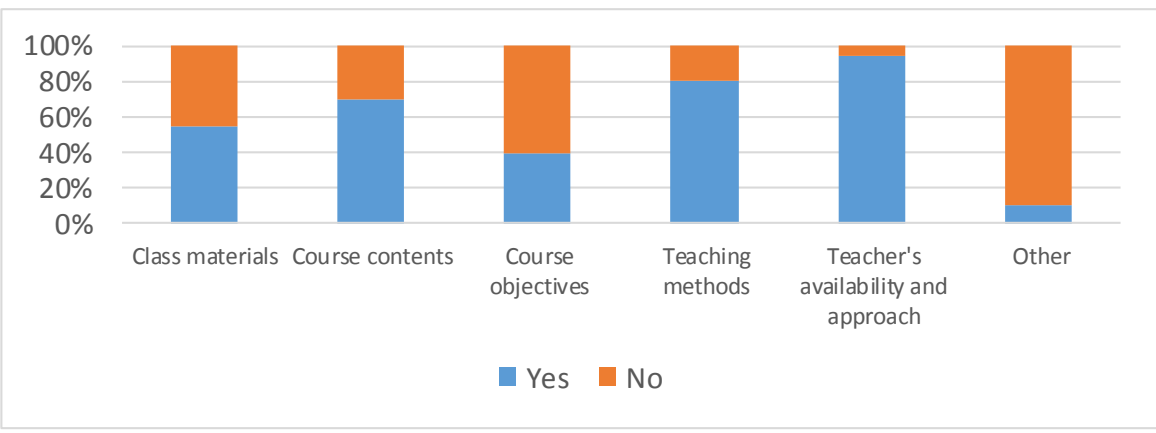

Fig. 5 Students' evaluation of the teaching process 
Fig. 5 clearly illustrates that all aspects of the teaching process, ranging from learning resources and contents to teaching resources, methods and approaches, are being evaluated by students. The results are consistent with the similar ones done by LesiakBielawska (2014), Salehi, Davari and Yunus (2015), Yeraldin Acosta Salazar, Brenes Burgos and Castro Murillo (2015), Manoochehri and Nemati (2016) and Celik (2018). Considering the fact that all of the participants who carry out course evaluations implement suggested adjustments to their courses, we can conclude that the ESP teachers profoundly care about their class performance, which they always try to improve pursuant to their students' suggestions.

\subsubsection{Challenges}

Regardless of teaching experience or a place where one teaches, each teacher faces challenges on a regular basis. The challenges our participants listed as something they frequently face with are large and mixed-ability groups of students, under motivated students, underappreciation by students and faculty management, time management, lack of ready-made course materials and insufficient content knowledge. The majority of the aforementioned challenges are recognized by several recent studies Suzani et al. (2011), Abdulaziz et al. (2012), Medrea and Rus (2012), Bardha and Jusufi (2017), Luo and Garner (2017) done on different nationality ESP teachers, which points to universality of the issue.

The participants were asked to provide solutions to the challenges and they listed smaller student groups, more academic skill-based classes, better coursebooks and a closer cooperation with subject specialists as responses to overcome the detected obstacles. These solutions are definitely something faculty management should address in order to help improve ESP courses development and enhance the acquired skills quality of the future graduates.

\section{CONCLUSION}

Pedagogical conceptualization of content knowledge has been unjustly marginalized and under explored. The issue of PCK is critical because teachers' possession of content knowledge does not imply successful knowledge transfer to students. Everyone has probably heard or said a sentence "He/she might be an expert in the field but he/she cannot teach." This is because a teacher has content knowledge but lacks techniques, methods, insights and understandings of the educational context to transfer knowledge.

This paper aimed to study ESP teachers' teaching experience. Forty seven ESP teachers working at 7 Croatian universities voluntarily participated in the anonymous survey which was analyzed in SPSS. A lower percentage of the participants carry out placement and needs-analysis tests probably due to a lack of time and administration restrictions should they decide to implement students' suggestions. When deciding which contents to teach, the teachers prioritize and put more emphasis on teaching specialized vocabulary, speaking and presentation skills recognizing those skills as the most important for students. One of the challenges the teachers listed is material design as 
there are no appropriate ready-made materials so the teachers have to compile their own. When compiling, the teachers use multiple resources, which is very time-consuming. A vast majority of the teachers do not cooperate with content teachers on material design even though they recognize the synergy as a productive relationship. The teachers are moderately insecure about content knowledge, which comes as no surprise because they were not educated for other fields. However, the higher percentages on pedagogical content knowledge indicate that the teachers do thorough preparations on specialized topics to be taught in order to present them in an appropriate and appealing way. Finally, the teachers assess their students' knowledge efficiently and evaluate their courses conducting surveys upon which they implement students' suggestions.

Taking everything into account, we can conclude that ESP teaching is a very challenging job, yet ESP teachers go to great lengths to provide their students with interesting materials and assignments, engage them in the teaching process and make ESP classes as places where they would acquire sought and desired skills thus demonstrating a high level of pedagogical content knowledge.

\section{REFERENCES}

Abdulaziz, Maimoona, Kazim Shah, Sayed, Mahmood, Rashid and Fazal el Haq, Hafiz. "Change From A General English Teacher To An ESP Practitioner: Issues And Challenges In Pakistan." Interdisciplinary Journal of Contemporary Research in Business 4, no. 1 (2012). 434-465.

Abell, Sandra K. "Research on science teacher knowledge." In Handbook of research on science education, edited by Sandra K. Abell and Norman G. Lederman, 1105-1149. Mahwah, N.J.: Lawrence Erlbaum Associates, 2007.

Akbari, Ramin and Moradkhani, Shahab. "Is a degree relevant? A comparison of pedagogical thought units of teachers with and without ELT-related academic credentials." Australian Journal of Teacher Education 37, no. 12 (2012). 77-93.

Alsamadani, Hashem Ahmed. "Needs Analysis in ESP Context: Saudi Engineering Students as a Case Study." Advances in Language and Literary Studies 8, no. 6 (2017). 58-68.

Atefi Boroujeni, Samira and Moradian Fard, Fateme. "A Needs Analysis of English for Specific Purposes (ESP) Course for Adoption of Communicative Language Teaching: A Case of Iranian First-Year Students of Educational Administration." International Journal of Humanities and Social Science Invention 2, no. 6 (2013). 35-44.

Božić Lenard, Dragana, Ferčec, Ivanka and Liermann-Zeljak, Yvonne. "Grammar or vocabulary - students' friends or foes?" In Establishing Predominance of English for Specific Purposes within Adult English Language Teaching, edited by Nadežda Stojković and Burkšaitienè, Nijolè, 1-26. Newcastle upon Tyne: Cambridge Scholars Publishing, 2018.

Božić Lenard, Dragana and Pintarić, Ljiljana. "Comparison of employers' and students' perceptions regarding communication skills." Journal of Teaching English for Specific and Academic Purposes 6, no. 1 (2018). 63-82. 
Celik, Handan. “A Closer Look into an ESP Course Through Students' End-Of-Course Evaluations: A Case Study." Journal of Teaching English for Specific and Academic Purposes 6, no. 1 (2018). 125-139.

Chick, Helen. "Choice and use of examples as a window on mathematical knowledge for teaching." For the Learning of Mathematics 29, no. 3 (2009). 26-30.

Chin-Ling, Lee. "Principles and Practices of ESP Course Design - A Case Study of a University of Science and Technology." International Journal of Learning, Teaching and Educational Research 15, no. 2 (2016). 94-105.

Deveci, Tanju and Nunn, Roger. "Comm151: A project-based course to enhance engineering students' communication skills." Journal of Teaching English for Specific and Academic Purposes 6, no. 1 (2018). 27-42.

Deveci, Tanju and Nunn, Roger. "Intrapersonal communication as a lifelong learning skill in engineering education." Journal of Higher Education 7, no. 1 (2017). 1-10.

Ball, Deborah L., Thames, Mark H. and Phelps, Geoffrey. "Content knowledge for teaching: What makes it special?" Journal of Teacher Education 59, no. 5 (2008). 389-407.

Bardha Gashi, and Jusufi, Jasmin. "Analysis of ESP Courses Profile: Bridging the Gap Between ESP Challenges and 21st Century Skills." European Journal of Language and Literature Studies 9, no. 1 (2017). 63-69.

Dapaepe, Fien, Verschaffel, Lieven and Kelchtermans, Geert. "Pedagogical content knowledge: A systematic review of the way in which the concept has pervaded mathematics educational research." Teaching and Teacher Education 34 (2013). 1225.

Fadel, Sahar and Elyas, Tariq. „ESP Needs Analysis to Integrate a Scientific Reading Program in the English Language Institute at King AbdulAziz University." International Journal of Educational Investigations 2, no. 4 (2015). 14-27.

Fenollera, Maria, Lorenzo, Jaime, Goicoechea, Itziar and Badoui, Aida. "Interdisciplinary Team Teaching." In DAAAM International Scientific Book, edited by Branko Katalinić, 585-600. Austria: DAAAM International, 2012.

Gifford, Frederick How to enrich your vocabulary? New Delhi: Cyber Tech Publications, 2013.

Gorska-Porecka, Bozena. "The Role of Teacher Knowledge in ESP Course Design." Studies in Logic, Grammar and Rhetoric 34, no. 47 (2013). 27-42.

Hill, Heather, Ball, Deborah, Schilling, Stephen. "Unpacking pedagogical content knowledge, conceptualizing and measuring teachers' topic specific knowledge of students." Journal for Research in Mathematics Education 39, no. 4 (2008). 327-400.

Hossain, Jamal. "ESP Needs Analysis for Engineering Students: A Learner Centered Approach." Journal of PU 2, no. 2 (2013). 16-26.

Hutchinson, Tom and Waters Alan. "English for Specific Purposes: A Learning-Centred Approach." In New Directions in Language Teaching, edited by Howard B. Altman and Peter Strevens, 106-127. Cambridge: CUP, 2010.

Little, Amanda and Hoel, Anne. "Interdisciplinary Team Teaching: An Effective Method to Transform Student Attitudes." The Journal of Effective Teaching 11, no. 1 (2011). 36-44. 
Lesiak-Bielawska, Elzbieta Danuta. "Key Aspects of ESP Material Selection and Design." English for Specific Purposes World 46 (2015). Retrieved from http://www.esp-world.info/Articles_46/ESPmaterialsLesiak-Bielawska.pdf

Lesiak-Bielawska, Elzbieta. Danuta. "English for instrumentalists: Designing and evaluating an ESP course." English for Specific Purposes World 43, no. 15. (2014). 1-32.

Luo, Jing and Garner, Mark. "The Challenges and Opportunities for English Teachers in Teaching ESP in China." Journal of Language Teaching and Research 8, no. 1 (2017). 81-86.

Manoochehri, Mohammad Amin and Nemati, Azadeh. "Evaluation of Computer Engineering ESP Course from Students' Viewpoints." British Journal of Education, Society and Behavioural Science 14, no. 2 (2016). 1-13.

Medrea, Nicoleta and Rus, Dana. "Challenges in Teaching ESP: Teaching Resources and Students' Needs." Procedia Economics and Finance 3 (2012). 1165-1169.

Mishra, Punya and Koehler, Matthew J. "Technological pedagogical content knowledge: A framework for integrating technology in teachers' knowledge." Teachers College Record 108, no. 6 (2006). 1017-1054.

Moradkhani, Shahab, Akbari, Ramin, Ghafar Samar, Reza and Kiany, Gholam Reza. "English Language Teacher Educators' Pedagogical Knowledge Base: The Macro and Micro Categories." Australian Journal of Teacher Education 38, no. 10 (2013). 122-141.

Park, Soonhye and Oliver, Steve. "Revisiting the conceptualisation of pedagogical content knowledge (PCK): PCK as a conceptual tool to understand teachers as professionals." Research in Science Education 38, no. 3 (2008). 261-284.

Sahli, Naima. "The challenges of teaching ESP in the department of political sciences." Journal of Teaching English for Specific and Academic Purposes 4, no. 2 (2016). 373-380.

Salehi, Hadi, Davari, Ameneh and Yunus, Melor. "Evaluation of an ESP Course of Qur'anic Sciences and Tradition." International Education Studies 8, no. 1 (2015). 29-37.

Shulman, Lee S. "Those who understand: Knowledge growth in teaching." Educational Researcher 15 (1986). 4-14.

Shulman, Lee S. "Knowledge and teaching: Foundations of the new reform." Harvard Educational Review 57, no. 1 (1987). 1-22.

Suzani, Samad Mirza, Yarmohammadi, Lotfollah and Yamini, Mortaza. "A critical review of the current situation of teaching ESP in the Iranian higher education institutions." The Iranian EFL Journal 7, no. 6 (2011). 179-204.

Upton, Thomas A. "Current issues in ESP materials." Taiwan International ESP Journal 4, no. 1 (2012). 45-65.

Yeraldin Acosta Salazar, Ana, Brenes Burgos, Carolina and Castro Murillo, Jackeline. "Evaluating an English for Specific Purposes Course for Law Students." Revista de Lenguas Modernas 23 (2015). 263-283.

Zembylas, Michalinos. "Emotional ecology: The intersection of emotional knowledge and pedagogical content knowledge in teaching." Teacher and Teacher Education 23 (2007). 355-367. 